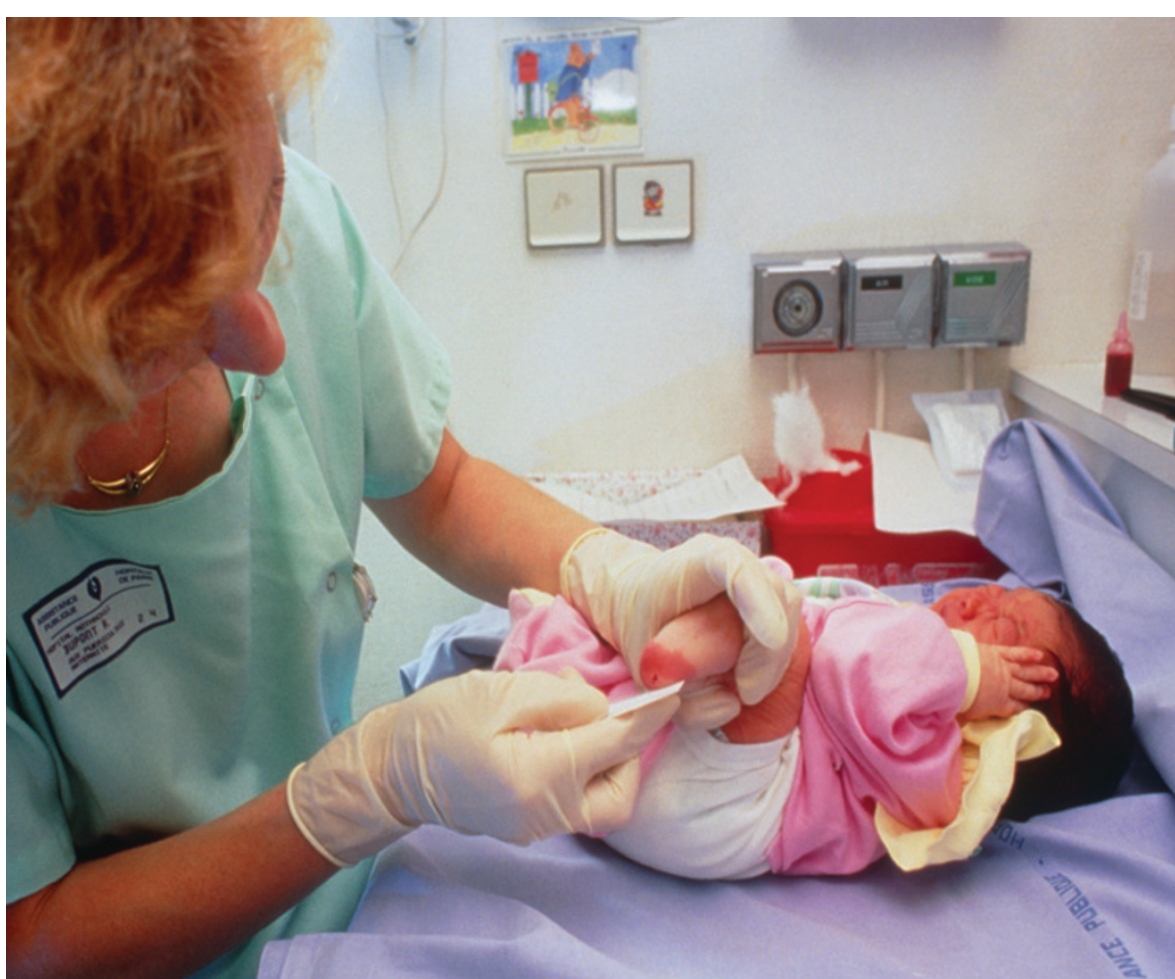

A nurse takes blood from the heel of a newborn baby to screen for the amino-acid disorder phenylketonuria.

GENETICS

\title{
Testing infant destinies
}

\section{Henry Greely hails a study examining California's experience of mandatory newborn genetic screening.}

A $\mathrm{t}$ the heart of Saving Babies? are the tiny consultation rooms in a Southern California academic medical centre, crowded with families, genetics staff, medical students and "nosy ethnographers, who did their best to take up as little space, and air, as possible". Medical sociologist Stefan Timmermans and medical anthropologist Mara Buchbinder may have been holding their breath, but their observations provide a fascinating portrait of the state's expanded newborn-genetic-screening programme, and of the lives it has changed.

In 2005, California became one of the first US states to adopt recommendations to expand its mandatory newborn genetic screening to more than 50 conditions, adding rarer, less well-understood ones like the organic acid oxidation disorder 3-MCC to those such as phenylketonuria (PKU) and sickle-cell disease. Saving Babies? covers the history of newborn genetic testing, but is

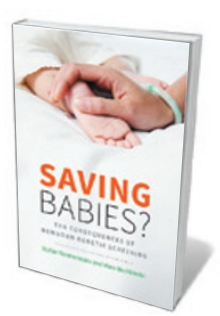

Saving Babies?

The Consequences

of Newborn

Genetic Screening

STEFAN TIMMERMANS

AND MARA

BUCHBINDER

Univ. Chicago Press:

2012. 320 pp. \$30,

$£ 19.50$

it is not clear how many babies received effective treatment as a result of the testing programme, nor how many lives were saved. Quite clear, however, are the difficulties of plugging a universal "entitlement" to a screening test into the complex and often irrational US health-care system.

The book begins with Scott and Renee Baio, a US celebrity couple whose daughter Bailey tested positive for glutaric aciduria type 1 (GA1), a condition involving an inability to process certain amino acids. Her test turned out to be a false positive, but during the harrowing wait to find out, her father pledged that if Bailey did not have the disease he would support children who did. Surprisingly, in light of the distress that accompanied the testing process, the Baios became strong advocates for newborn testing. Their experience of the uncertainties of genetic testing sets the stage for the rest of the book.

The historical overview of newborn screening is excellent, covering both its 1960 s origins with PKU screening and the programme's expansion throughout the United States, starting in 2005. At least three factors drove the expansion. One was the discovery that an existing technology, tandem mass spectroscopy, could be used to gauge the levels of many different proteins simultaneously, and hence cheaply. Another was pressure from organizations focusing on genetic diseases, such as the March of Dimes. And a third was an influential set of recommendations from the American College of Medical Genetics (ACMG), supporting expanded screening.

Timmermans and Buchbinder powerfully convey how the screening programme converted some children into "patients-inwaiting". One child in their study underwent repeated rounds of GA1 testing while his parents remained uncertain whether their child was actually a 'patient'. This uncertainty, in part a function of the tests but also of our limited knowledge about many of the newly added conditions, can affect the lives of children and parents profoundly.

The authors show how new evidence from the screening programme changed medical understanding of some of the conditions tested for, and how clinicians used shifting definitions of 'normal' to lead parents through various stages of their children's conditions. The authors examine the Californian programme's record in disease prevention and saving lives, goals that they show were inevitably compromised by flaws in the health-care system. They conclude that, at least for the metabolic diseases added into expanded screening, the results are not clear.

Saving Babies? isn't perfect. I would have liked some exploration of why, in its 2005 report, the ACMG moved from being cautious about neonatal screening to enthusiastic about its expansion.

\section{DNATURE.COM}

\section{For fetal}

diagnostics, see:

go.nature.com/1xwdzu 
The book may also suffer from a kind of sampling bias. The families the authors saw most were those trapped in the most difficult situations - of either medical uncertainty or medical danger. They saw less of families for whom the screening was beneficial, particularly those whose children were diagnosed with a condition already in the screening programme before 2005. So the picture may be unduly gloomy. Finally, more discussion of how newborn screening is (or is not) done outside the United States would have contextualized this California-based study.

The book does highlight some broader problems about scholarly work in this area. The first is its audience. Although, happily, the book is largely jargon-free, readers without much genetic knowledge may struggle to follow the valuable information for shaping screening policy, or be frustrated by the medical-sociology focus on observation rather than an assessment of alternative policies. Good policy will require input from many disciplines. All of us, from whatever discipline, need to work hard to make our findings useful to others.

The second problem is time. After the 2005 adoption of expanded screening in California, the authors studied families from November 2007 through to July 2010. The book will be read in 2013. That time lag was largely unavoidable, but by the time the programme can be assessed, it and its settings are no longer the same. The screening programme itself has already changed our understanding of some of the conditions in ways that undercut some of the authors' findings. Meanwhile, the US health-care system is in the process of transformation.

And newer challenges are at hand. Today, whole-exome and whole-genome sequencing are being used clinically, often for children with conditions as poorly understood as those described here. With the plunging cost of sequencing, I think newborn sequence screening will not be far behind. And the challenges will not wait for a baby's birth. In the United States and elsewhere, several companies are already using sequencing technologies for prenatal testing for aneuploidies (disorders in which the fetus has the wrong number of chromosomes) using a simple maternal blood draw within the first trimester; wider applications are surely coming.

How can we implement and assess new technologies competently when the world is changing too fast for the assessors? That, to me, is the most disturbing question raised by this excellent book.

Henry T. Greely is the Deane F. and Kate Edelman Professor of Law; professor (by courtesy) of genetics; and director of the Center for Law and the Biosciences at Stanford University, California. e-mail:hgreely@stanford.edu

\section{Books in brief}

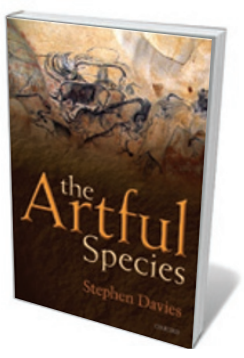

The Artful Species: Aesthetics, Art, and Evolution

Stephen Davies OXFORD UNIV. PRESS 320 pp. £25 (2012)

This spare and elegant treatise by philosopher of aesthetics Stephen Davies posits that art is part of human nature, and is tied in a number of ways to human evolution. Moreover, he argues, the evidence could stretch back at least 400,000 years - to a blood-red quartzite hand axe dubbed Excalibur by the archaeologists who dug it up. Davies marshals findings in disciplines ranging from neuroscience, ethology and evolutionary biology to the arts, musicology and literature. Ultimately, he says, our artistic behaviour is both "puzzling and magnificent", as we shoulder the heavy costs with perennial zeal.

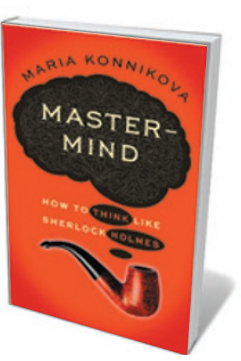

Mastermind: How to Think Like Sherlock Holmes

Maria Konnikova VIKING 288 pp. \$26.95 (2013)

Devotees of Arthur Conan Doyle's conundrum-cracker will be thrilled by this portmanteau of strategies for sharpening cognitive ability.

Scientific American columnist Maria Konnikova mixes psychology and neuroscience with Holmesian technique and insights on everything from information storage (Holmes's 'brain attic') to observation, awareness and razor-sharp deduction. A few hours in Konnikova's company and, along with Holmes, you might intone, "give me the most abstruse cryptogram or the most intricate analysis, and I am in my own proper atmosphere" (The Sign of Four, 1890).

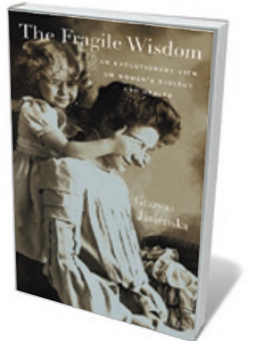

\section{The Fragile Wisdom: An Evolutionary View on Women's Biology} and Health

Grazyna Jasienska HARVARD UNIV. PRESS 298 pp. £25.95 (2013)

Women may aim for perfect health through diet, exercise and close attention to medical advice, but still develop breast cancer or osteoporosis. Reproductive fitness often wars with general physical fitness over a woman's lifetime, argues public-health specialist Grazyna Jasienska. Drawing on a raft of research in evolutionary biology and beyond, she points to factors such as the disjunction between 'palaeo' and current lifestyles, hormonal disparities and longer lifespans as key to informing disease-prevention strategies.

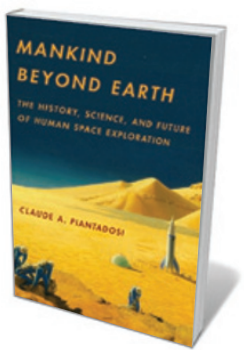

Mankind Beyond Earth: The History, Science, and Future of Human Space Exploration

Claude A. Piantadosi ColumbIA UNIV. Press 336 pp. \$35 (2013)

Despite difficulties such as cosmic radiation, huge distances, nearvacuum conditions and zero gravity, manned space flight still ignites the imaginations of millions. Medical doctor Claude Piantadosi fans the flames by boldly going into the past and possible future of US space exploration. This is a chronicle at warp speed, covering the science of space exploration; robots, spacecraft and the International Space Station; NASA's glory years; and the constraints on kick-starting 'cheap' space transportation.

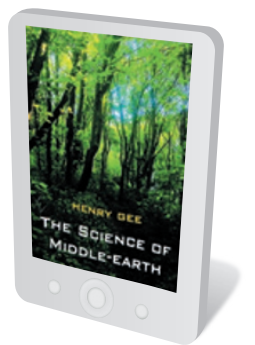

The Science of Middle-earth

Henry Gee JILL GRINBERG LITERARY MANAGEMENT Available for Kindle only $\$ 4.99$ (2012)

Repeat immersions in Middle-earth beckon again as Peter Jackson's first instalment of The Hobbit trilogy, An Unexpected Journey, opens in cinemas. Nature senior editor Henry Gee offers a revised and reissued guide to the science in J. R. R. Tolkien's fictional world. This is a completist's feast, from the glow of Bilbo's Elvish blade Sting (possibly the result of a chemical sensor "specifically tuned to Orkish exhalations") to the aerodynamic unfeasibility of a Balrog's wings. 